Fukushima J. Med. Sci.,

Vol. 58, No. 1, 2012

[Original Article]

\title{
CLINICAL EVALUATION OF DENDRITIC CELLS VACCINATION FOR ADVANCED CANCER PATIENTS AT FUKUSHIMA MEDICAL UNIVERSITY
}

\author{
IZUMI NAKAMURA ${ }^{1)}$, MASASHI KANAZAWA ${ }^{1)}$, YU SATO ${ }^{1)}$, ATSUSHI IRISAWA ${ }^{2)}$, \\ TADAYUKI TAKAGI ${ }^{2)}$, TAKASHI OGATA ${ }^{2)}$, SHOGO KASHIMURA ${ }^{3)}$, \\ AKIRA KENJO ${ }^{3)}$, HIROYUKI SUZUKI ${ }^{3)}$, MASAHIKO SHIBATA ${ }^{4}$, \\ TATSUO SHIMURA ${ }^{4)}$, HIROMASA OHIRA ${ }^{2)}$, MITSUKAZU GOTO ${ }^{3)}$, \\ SEIICHI TAKENOSHITA ${ }^{1)}$ and HITOSHI OHTO ${ }^{5)}$

\begin{abstract}
${ }^{1)}$ Department of Organ Regulatory Surgery, ${ }^{2)}$ Department of Gastroenterology and Rheumatology, ${ }^{3)}$ Department of Organ Regererative Surgery, ${ }^{4)}$ Department of Tumor Host Bioscience, ${ }^{5)}$ Department of Blood Transfusion and Transplantation Immunology
\end{abstract}

(Received October 5, 2011, accepted February 2, 2012)

\begin{abstract}
Dendritic cells (DCs) are powerful antigen-presenting cells (APCs) that have attracted attention in recent years from the viewpoint of DC vaccine therapy against cancer. However, the existence of a strongly immunosuppressed state in cancer-bearing individuals inhibits DC maturation, which is one of the problems facing anti-cancer DC vaccine therapy. Isolated DCs loaded with tumor antigen ex vivo and administered as a cellular vaccine have been found to induce protective and therapeutic anti-tumor immunity in experimental animals. In clinical trials of DC vaccination for cancer patients, induction of anti-tumor immune responses and tumor regression has been observed. In this study, eighty-one advanced cancer patients unsuccessfully treated by established treatment in individual cases were selected between January 2002 and May 2007 at Fukushima Medical University. The usefulness of DC therapy was investigated by intradermal injection of peptide pulsed DCs for an overall objective response rate of $28.0 \%$. Furthermore, direct injection of immature DCs into tumor extracted an overall objective response rate of $35.7 \%$, and especially $40.0 \%$ for advanced pancreatic cancer by using endoscopic ultrasound-guided fine-needle injection technique as a novel approach. These results indicate that DC-based vaccination could be a promising treatment modality for various cancers, however multiple hurdles must be cleared before the development of an affordable DC-based vaccination can be used worldwide.
\end{abstract}

Key words : dendritic cell, vaccination, advance cancer

\section{INTRODUCTION}

Human tumors express a number of protein antigens that can be recognized by $\mathrm{T}$ cells, thus providing potential targets for cancer immunotherapy. Dendritic cells (DCs) are rare leukocytes that are uniquely potent in their ability to present antigens to $\mathrm{T}$ cells, and this property has prompted their recent application to therapeutic cancer vaccines. Isolated DCs loaded with tumor antigen ex vivo and administered as a cellular vaccine have been found to induce protective and therapeutic anti-tumor immunity in experimental animals. In pilot clinical trials of DC vaccination for patients with non-Hodgkin's lymphoma and melanoma, induction of anti-tumor immune responses and

中村 泉, 金澤匡司, 佐藤 雄, 入澤篤志, 高木忠之, 尾形 隆, 樫村省吾, 見城 明, 鈴木弘行, 柴田昌彦, 志村龍男, 大平弘正, 後藤満一, 竹之下誠一, 大戸 斉

Corresponding author : Izumi Nakamura E-mail address : izumin@fmu.ac.jp

https://www.jstage.jst.go.jp/browse/fms http://www.fmu.ac.jp/home/lib/F-igaku/ 
tumor regression has been observed ${ }^{1)}$. Additional trials of DC vaccination for a variety of human cancers are under way, and methods for targeting tumor antigens to DCs in vivo are also being explored. Exploitation of the antigen-presenting properties of DCs thus offers promise for the development of effective cancer immunotherapies. In this study, the usefulness of DC therapy was investigated by intradermal injection of peptide pulsed DCs with/ without chemotherapy, which are direct injection of immature DCs into tumor as well as endoscopic ultrasound-guided fine-needle injection (EUS-FNI) of immature DCs into advanced cancers.

\section{MATERIAL AND METHODS}

In this study, eighty-one advanced cancer patients unsuccessfully treated by established treatment in individual cases were selected between January 2002 and May 2007 at Fukushima Medical University. The study protocol conformed to the ethical guidelines of the 1975 declaration of Helsinki and was approved by the ethical committee of Fukushima Medical University. All patients provided informed consent before treatment. Demographic characteristics of the individuals treated with DCs vaccines are shown in Table 1 . Of the eighty-one patients treated, 12 had pancreatic cancer, 15 had gastric cancer, 14 had colorectal cancer, 10 had biliary cancer, 8 had lung cancer, 7 had breast cancer, 3 had hepatoma, 2 had cholangiocarcinoma, 4 had esophageal cancer, 2 had melanoma and 4 had other types of cancer (Table 1).

Isolation of peripheral blood monocytes and DCs induction

Forty $\mathrm{ml}$ of heparinized peripheral blood was collected from the patients' vein and separated using the Ficoll density gradient centrifugation method. $1 \times 10^{8}$ peripheral blood mononuclear cells (PBMCs) were obtained from the buffy coat. $1 \times 10^{9} \mathrm{PBMCs}$ were obtained from the plasmapheresis using the same method. Of the eighty-one patients, 11 cases with blood collected from the patients' vein and 70 cases with PBMCs from plasmapheresis were selected corresponding to the individual conditions (Table 2). The PBMCs were cultured in RPMI medium, the monocyte fraction from the adhesion cells were co-cultured with $100 \mathrm{ng} / \mathrm{ml} \mathrm{GM-CSF}$ and $50 \mathrm{ng} / \mathrm{ml} \mathrm{IL}-4$ for 7 days to induce DCs. The suspension of DCs was confirmed with FITC-or $\mathrm{PE}$-conjugated monoclonal antibodies against CD40, CD80, CD86, HLA-DR cell surface antigen, and then analyzed using FACS Calibur flow cytometer

Table 1. Patient Characteristics

\begin{tabular}{llcc}
\hline & & Patients & Percentage \\
\hline Sex & Male & 48 & $59 \%$ \\
Female & $\sim 30$ & 33 & $41 \%$ \\
& $30 \sim 40$ & 1 & $1 \%$ \\
& $40 \sim 50$ & 4 & $5 \%$ \\
$50 \sim 60$ & 12 & $15 \%$ \\
$60 \sim 70$ & 24 & $30 \%$ \\
Disease & 24 & $30 \%$ \\
& 80 $\sim 80$ & 14 & $17 \%$ \\
& pancreatic cancer & 2 & $2 \%$ \\
gastric cancer & 12 & $15 \%$ \\
colorectal cancer & 15 & $19 \%$ \\
cholangiocarcinoma & 14 & $17 \%$ \\
& biliary cancer & 2 & $2 \%$ \\
lung cancer & 10 & $12 \%$ \\
breast cancer & 8 & $10 \%$ \\
hepatoma & 7 & $9 \%$ \\
esophageal cancer & 3 & $4 \%$ \\
melanoma & 4 & $5 \%$ \\
others & 2 & $5 \%$ \\
\hline
\end{tabular}


Table 2. Method of DC therapy

\begin{tabular}{lll}
\hline Extraction & Apheresis & 70 \\
& Peripheral blood & 11 \\
Method & Peptide pulsed DCs & 53 \\
& with chemotherapy & 20 \\
& without chemotherapy & 33 \\
& DC injection & 28 \\
by direct injection & 18 \\
& by EUS guided FNI & 10 \\
\hline
\end{tabular}

(FACScan). $\quad 1 \times 10^{7}, 1 \times 10^{8} \mathrm{DCs}$ were obtained from the $40 \mathrm{ml}$ peripheral blood and plasmapheresis, respectively. Culture was manufactured under GMP grade quality except TNF- $\alpha$, and before the administration to the patients, DCs were finally checked under endotoxin and $\beta-\mathrm{D}$ glucan.

\section{Maturation of DCs}

TNF- $\alpha$ was added to the final concentration of $10 \mathrm{ng} / \mathrm{ml}$ on day 7 after initiating culture, followed by conformation with monoclonal antibody against CD83 using FACScan.

\section{Peptide pulse of maturation DCs}

Pulsed peptides were selected by high serum CEA or CA19-9 levels, pathological findings of antigen-specific examination such as HER2, MUC-1, AFP with individual HLA typing. The mature DCs were stimulated for $4 \mathrm{hr}$ twice with $10 \mathrm{ug} / \mathrm{ml}$ selected peptide for each individual patient.

\section{Method of administration}

a) Peptide pulsed DC therapy

Synthetic peptide approaches require the identification of tumor-specific antigens for individual tumors. Intradermal injection near the regional lymph node of peptide pulsed DCs with/without chemotherapy was performed.

b) Injection of immature DCs into tumor

Injected intra-tumor DC is expected to work phagocytosis of the tumor as a localized effect, the consequent cytotoxic T lymphocytes (CTLs) induction in the tumor and the regional lymph nodes, resulting in a systemic effect. Injection of immature DCs into tumor was performed by means of simple syringe or endoscope approach as well as endoscopic ultrasound-guided fineneedle injection (EUS-FNI) as a novel approach. 10 advanced patients (7 pancreatic, 3 others) received intratumoral injection of a hundred million immature DCs at 2 to 3 sites using
EUS-FNI. DC was administered on days 1 and 15. The cycles were repeated every 28 days as much as possible. Physical and laboratory examinations assessed the potential vaccine toxicity.

\section{Evaluation of DC therapy}

Clinical end points were tumor response, and survival as well as individual tumor marker level such as CEA or CA19-9. Standard clinical response criteria were applied. Complete response (CR) was complete regression of all lesions lasting at least 1 month. Partial response (PR) was a greater than $50 \%$ decrease of lesions lasting more than 1 month. Mixed response (MR) was a regression of main pancreatic tumors, whereas other lesions remained stable or progressed. Stable disease (SD) was defined as a less than $25 \%$ size reduction with no newly developed lesions for more than 1 month. Progressive disease (PD) was defined as an increase of more than $25 \%$ in the sites of primary or metastatic lesions or the occurrence of new lesions.

\section{RESULTS}

\section{1) Intradermal injection of peptide pulsed DCs}

The vaccine treatments received by these patients are shown in Table 2. Peptide vaccines alone were administered to 53 (20 with/ 33 without chemotherapy) individuals using peptides derived from one of the following: cancer-testes antigens such as CEA, MUC-1, HER2 or AFP (Table 3). Of the thirty-three recipients of a peptide vaccine without chemotherapy, only 1 case showed a MR with a regression of main tumor and 3 cases showed a SD, for an overall objective response rate of $12.0 \%$. Of the twenty recipients of a peptide vaccine with chemotherapy, 2 cases showed a PR and 9 cases showed a SD, for an overall objective response rate of $55.0 \%$ (Table 4). Tumor markers have decreased to 2 stage IV cases of PR respectively. These two cases got survival duration for one year or more (Table 5). No remarkable complication associated with intradermal injection of the DCs, except 2 cases of mild fever, was noted.

\section{2) Injection of immature DCs into tumor}

Immature DCs were administrated into tumor in 28 individuals by using 18 direct injections and 10 EUS guided FNI (Table 2). Of the twenty-eight participants who were injected with immature DCs 
Table 3. Peptide vaccine immunization and immature DCs

\begin{tabular}{|c|c|c|c|c|c|c|}
\hline \multirow{2}{*}{ Disease } & \multirow{2}{*}{ Number } & \multicolumn{4}{|c|}{ Peptide pulsed DCs } & \multirow{2}{*}{$\begin{array}{l}\text { Injection of } \\
\text { immature DCs }\end{array}$} \\
\hline & & CEA & MUC-1 & HER-2 & $\mathrm{AFP}$ & \\
\hline pancreatic cancer & 2 & 1 & 2 & & & 10 \\
\hline gastric cancer & 12 & 7 & 6 & 2 & & 3 \\
\hline colorectal cancer & 12 & 10 & 4 & 6 & & 2 \\
\hline cholangiocarcinoma & 0 & & & & & 2 \\
\hline billiary duct cancer & 8 & 1 & 8 & 3 & & 2 \\
\hline lung cancer & 8 & & 8 & & & 0 \\
\hline breast cancer & 5 & 2 & 3 & 1 & & 2 \\
\hline hepatoma & 0 & & & & & 3 \\
\hline esophageal cancer & 3 & 2 & 1 & & & 1 \\
\hline melanoma & 0 & & & & & 2 \\
\hline others & 3 & 2 & 1 & & 1 & 1 \\
\hline
\end{tabular}

Table 4. Peptide pulsed DC Therapy (53 cases)

\begin{tabular}{c|cc|cccc}
\hline \multirow{2}{*}{} & \multicolumn{2}{|c|}{ Total (53) } & \multicolumn{2}{c}{ with chemotherapy (20) } & \multicolumn{2}{c}{ without chemoterapy (33) } \\
\cline { 2 - 6 } & Number & Percentage & Number & Percentage & Number & Percentage \\
\cline { 2 - 6 } PR & 2 & $3.70 \%$ & 2 & $10 \%$ & 0 & $0 \%$ \\
MR & 1 & $1.90 \%$ & 0 & $0 \%$ & 1 & $3 \%$ \\
SD & 12 & $23 \%$ & 9 & $45 \%$ & 3 & $9 \%$ \\
PD & 38 & $71.40 \%$ & 9 & $45 \%$ & 29 & $88 \%$ \\
\hline
\end{tabular}

Table 5. Objective responses to DC vaccine treatment

\begin{tabular}{|c|c|c|c|c|c|c|c|c|c|}
\hline \multirow[b]{2}{*}{ Case } & \multirow[b]{2}{*}{ Age } & \multirow[b]{2}{*}{ Sex } & \multirow[b]{2}{*}{ Disease } & \multirow[b]{2}{*}{ Stage } & \multirow[b]{2}{*}{ Metastasis } & \multirow[b]{2}{*}{ Treatment } & \multicolumn{2}{|c|}{ Clinical efficacy } & \multirow{2}{*}{$\begin{array}{l}\text { Survival } \\
\text { Duration } \\
\text { (Month) }\end{array}$} \\
\hline & & & & & & & $\begin{array}{l}\text { Tumor } \\
\text { Marker }\end{array}$ & Image & \\
\hline 1 & 45 & Female & breast cancer & IV & $\begin{array}{l}\text { contralatetal breast, } \\
\text { lymph node }\end{array}$ & Peptide & NST-439 $\downarrow$ & PR & 13 \\
\hline 2 & 62 & Male & lung cancer & IV & sacrum & Peptide & $\mathrm{CEA} \downarrow$ & PR & 12 \\
\hline 3 & 54 & Male & biliary cancer & $\mathrm{IVb}$ & peritoneum, ureter & Peptide & - & MR & 3 \\
\hline 4 & 54 & Male & pancreatic cancer & $\mathrm{IVb}$ & liver, peritoneum & Injection & CA19-9 $\downarrow$ & MR & 6 \\
\hline 5 & 54 & Male & pancreatic cancer & $\mathrm{IVb}$ & liver & Injection & CA19-9 $\downarrow$ & MR & 14 \\
\hline 6 & 61 & Male & pancreatic cancer & $\mathrm{IVb}$ & peritoneum & Injection & CA19-9 $\downarrow$ & MR & 16 \\
\hline 7 & 61 & Male & malignant melanoma & IV & lymph node & Injection & - & MR & 8 \\
\hline 8 & 63 & Female & gastric cancer & IV & lymph node & Injection & $\begin{array}{c}\text { CA19-9 } \\
\text { CEA } \downarrow\end{array}$ & MR & 6 \\
\hline 9 & 68 & Male & esophageal cancer & IVa & lymph node & Injection & - & MR & 20 \\
\hline
\end{tabular}

into tumor, six cases obtained a MR and four obtained a SD. Thus, the overall objective response rate for the treatment was $35.7 \%$ (Table 6). Fig. 1 shows a case of bile duct cancer intratumoral DCs injection response. CA19-9 and total bilirubin has been reduced by 5 times of $\mathrm{DC}$ injection without any other therapy.
Of the ten participants with advanced pancreatic cancer, 7 were administered into primary tumor using by EUS-FNI. Seven patients had been unsuccessfully treated (gemcitabine) for unresectable pancreatic cancer : stage IV patients with multiple liver metastasis and/or artery involvement and/ or with malignant ascites. All patients had histo- 
Table 6. Intratumoral DC injection (28 cases)

\begin{tabular}{c|cc|cccc}
\hline \multirow{2}{*}{} & \multicolumn{2}{|c|}{ Total (28) } & \multicolumn{2}{c}{ EUS-FNI (10) } & \multicolumn{2}{c}{ Others (18) } \\
\cline { 2 - 6 } & Number & Percentage & Number & Percentage & Number & Percentage \\
\cline { 2 - 6 } PR & 0 & $0 \%$ & 0 & $0 \%$ & 0 & $0 \%$ \\
MR & 6 & $21.40 \%$ & 2 & $20 \%$ & 4 & $18 \%$ \\
SD & 4 & $14.30 \%$ & 3 & $30 \%$ & 1 & $12 \%$ \\
PD & 18 & $64.30 \%$ & 5 & $50 \%$ & 13 & $70 \%$ \\
\hline
\end{tabular}

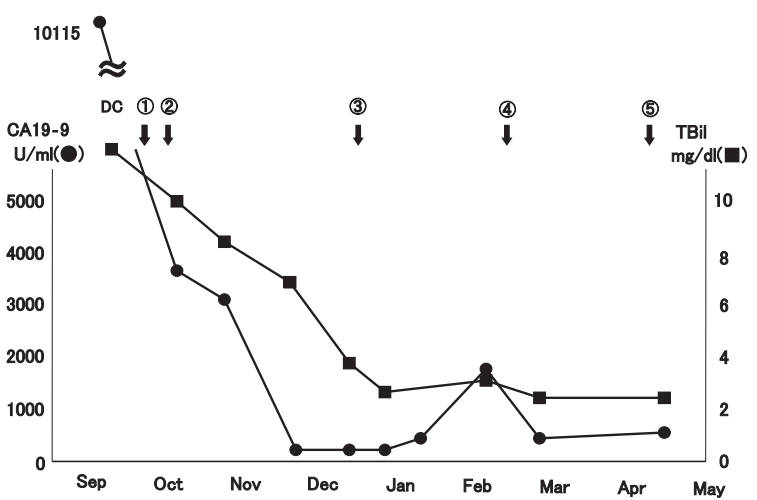

Fig. 1. Intratumoral DC injection for Biliary Cancer After DC injection, CA19-9 and total bilirubin were improved without other therapy.

logically proven intraductal adenocarcinoma by EUS-FNI. Five of seven patients received irradiation therapy before initial EUS-FNI of DCs to induce apoptosis and necrosis and produce tumorassociated antigens for DC cross-presentation. No complication associated with the EUS-FNI procedure was noted. The CA-19-9 levels decreased in 4 patients ; 2 showed a MR with regression of primary tumor. All DCs injections were tolerated with one case of Grade 1 fever and one case of redness of injection site.

\section{DISCUSSION}

New therapies for advanced cancer are needed to improve its prognosis. Immunotherapy, a novel approach, has been investigated for advanced cancer $^{2)}$. DCs, used in DC vaccine therapy against cancer, are potent antigen-presenting cells for induction of primary $\mathrm{T}$-cell dependent immune responses $^{3)}$. Many strategies for delivering antigens into DCs have been established in murine models and clinically tried. Synthetic peptide approaches require identification of tumor-specific antigens for individual tumors and demonstration of their recognition by CTLs.

Many clinical trials of DC-based vaccinations using autologous DCs and tumor-associated antigens have been conducted to assess the ability of these vaccines to induce clinical responses in cancer patients. In a review by Engell-Noerregaard et al. ${ }^{4}$, 57 of 626 malignant melanoma patients $(9 \%)$ showed objective response (20 CR and $37 \mathrm{PR}$ ) when treated with DC-based vaccinations, but no significant correlations were noted between those objective response and the tested parameters. Many initial vaccine studies used DCs charged with one or few tumor antigens, whereas the potential of DCs rests with their still untapped capacity to elicit a strong and broad immune attack to lessen the chance of tumor escape. In fact, the antitumor effect of active immunotherapy is a relatively simple implementation but has so far been weak ${ }^{5}$. Until now, the results obtained from reported clinical trials have not been sufficient enough for immunotherapy to become one of the standard cancer therapies.

In this study, peptide-pulsed DCs into intradermal tissue were administered to 53 individuals using peptides including CEA, HER2, MUC-1 and AFP. Of the recipients of the peptide vaccine, there was an overall objective response rate of $28.0 \%$ (15/ 53 cases), whereas, participants who were injected with immature DCs into tumor, had an overall objective response rate of $35.8 \%$. The first problem of $\mathrm{DC}$ therapy is that most injected DCs remain at the injection site; only a few migrate to the draining lymphoid tissue, just $1 \%$ in mice and human ${ }^{6}$. Secondly, cancer has many unknown antigens, antigenic peptides and CTL epitopes, presented by human advanced cancer, remain largely unidentified. We have intra-tumorally injected unloaded DCs into advanced cancer cells; they acquire and process tumor antigens in situ, migrate to regional lymphoid organs, and initiate a strong tumor-specific immune response. Therefore intra-tumoral injection appears preferable to intravenous or intradermal injections. Furthermore, the third problem is the existence of an immunosuppressive state in cancer individuals which leads to anergy and failure in CTLs induction and DC migration to the target 
organ. It has been reported that injected intratumor DCs are expected to work phagocytosis of the tumor as a localized effect. Consequently CTLs induction in the tumor and regional lymph nodes results in a systemic effect. Actually, we have undergone intra-tumor DCs injection therapy performed by means of EUS in 2 advanced gastric cancer cases. As a result, tumor makers and ascites of one case were on the decrease. The results indicate this method can be useful in advanced cancer patients ${ }^{7}$. Interventional EUS can approach pancreatic cancer cells using EUS-FNI technique ${ }^{2)}$. We performed EUS-FNI of DCs to investigate the feasibility, safety, and clinical response of EUS-FNI of unpulsed immature DCs into the pancreatic cancer refractory to systemic administration of gemcitabine. This is a pilot clinical study to inject unpulsed immature DCs into advanced pancreatic cancer cells. Median survival was 9.9 months, although previous studies reported 8 to 9 months as the mean for chemotherapy patients ; patients with peritonitis carcinomatosa face shorter survival. The poor prognosis associated with pancreatic cancer suggests that the response and survival data reported here for intratumoral injection of DCs are encouraging. These data indicate that intratumoral injection of unpulsed DCs into the pancreatic cancer using EUS-FNI is safe and can induce some clinical responses in patients with advanced diseases.

It is shown that the therapeutic effect improves immunotherapy using DCs with chemotherapy, leads to tumor regression and enhanced survival $^{8)}$. Chemotherapy present with endogenous antigen by the cytotoxic effect and causes the immunity induction. We confirmed that peptide pulsed DC therapy with chemotherapy has a clinical significance without chemotherapy. Of the thirty-three recipients of peptide vaccine without chemotherapy, only one case showed a MR and three showed a SD, for an overall objective response rate of $12.0 \%$. Of the twenty recipients of peptide vaccine with chemotherapy, two showed a PR and nine showed a SD, for an overall objective response rate of $55.0 \%$.

The selection of appropriate medicine is also important. In basic examinations, we demonstrated that about $60 \%$ of gastric cancer cells led to apoptosis with both paclitaxel (TXL) and docetaxel (TXT). Expression of Toll-like receptor (TLR)-4 mRNA in DCs was up-regulated by TXT, not by TXL. CTLs were induced by DCs pulsed with tumor cell lysate and apoptotic cells showed a similar killing activity to target cells. These results suggest that TXT appears to be an optimal antican- cer agent for combination therapy with chemotherapy and tumor specific immunotherapy using dendritic cells in gastric cancer ${ }^{9)}$.

Vaccine studies need to be accompanied by indepth immune monitoring to define assays for protective lymphocytes, the presence of which correlates with tumor regression and/or improved survival. CTL assay and delayed-type hypersensitivity (DTH) were used in monitoring cases of peptide pulsed DC subcutaneous vaccination therapy. CTL assay and DTH using CEA652 (9) that carried out at our facilities were verified ${ }^{10)}$. One out of ten cases (10\%) was SD, and 3 out of 10 cases were the induction of the CTL precursor observed for CTL assay in the peripheral blood of patients after the completion of 1 cycle (administered three times). In two cases, positive conversion was observed for DTH reaction. For the SD case, both CTL induction and positive conversion for DTH was observed. A reduction of the CEA value was observed in 3 patients among the 9 cases of PD. While the usefulness of CTL assay and DTH in monitoring cannot be determined solely by verification at this time, the possibility of observing many clinical reactions could be shown for CEA652 (9) in cases where positive conversion was observed. de Vries $e t$ al. reported a correlation between the presence of peptide-related T cells in DTH-infiltrating lymphocytes (DIL) of Stage IV melanoma patients and a prolonged PFS. The median PFS of 8 patients with tumor-reactive T cells in the DIL was 17 months, whereas that of 18 patients without them was only 2 months $(P=0.0012)^{11}$. In addition, a correlation was found between DTH-positive responses against tumor lysate and post-vaccination survival in the other trial ${ }^{12)}$. The post-vaccination survival of 11 patients with DTH responses was 17.2 months, whereas that of 9 patients without them was 8.6 months $(P=0.026)$. These results suggest that $\mathrm{T}$ cell responses at skin sites play an important role for OS, but not for tumor reduction. However, only a portion of patients showed reactions and thus overall benefits might not be provided by the present protocols of the DC-based vaccine.

DC vaccines are being tried only in late-stage cancer patients who are immunosuppresed as a result of extensive radiation, chemotherapy and/or large tumor burdens. Patient immune response is important in immunotherapy ${ }^{13)}$. We administered DCs to one postoperative advanced pancreatic cancer patient as adjuvant chemotherapy. This patient survived for over six years. In addition, we conducted a phase I study of preoperative intratumoral 
DCs based immunotherapy for advanced resectable pancreatic cancer patients. Based on our previous findings, DCs and OK-432 were directly injected into the tumor in 5 patients by EUS-FNI. In this series, there were no major complications expect in one patient undergoing distal pancreatectomy and reconstruction of common hepatic artery developed ruptured pseudoaneurysm due to pancreatic fistula. Histological lytic necrosis of tumor was found in association with marked inflammatory response surrounding/within the tumor. Giant cells indicating generation of DTH response were also found. These histological features were never found in pancreatic cancer patients without DC immunotherapy. Lymphocyte phenotype in regional lymph nodes was CD4 dominant $(\mathrm{CD} 4>\mathrm{CD} 8)$ and lymphocytic cytotoxity was enhanced in a dose-dependent manner. One patient died of a hepatic metastasis 16 months post operation, but the remaining 4 patients are disease-free from 2 months to 2 years.

The identification of human tumor antigens using various molecular biological and immunological techniques enabled us to develop immunotherapy in a more scientific way. More emphasis is needed on DC quality, by testing DC for their capacity to induce helper and killer $\mathrm{T}$ cells with a high avidity for tumor antigens but few Treg cells. Treatment of head and neck squamous cell carcinoma patients with $1,25(\mathrm{OH}) 2 \mathrm{D} 3$ reduced levels of immune inhibitory CD34+ cells while increasing maturation of dendritic cells ${ }^{14)}$. Since oral administration of PSK during DC therapy possibly induces $\mathrm{DC} 1$ and Th1 dominance resulting in enhancement of CTLs induction, the vaccination effect is expected to persist even in the immunosuppressive state $^{15,16)}$. Peptides derived from over-expressed p53 protein are presented by class I MHC molecules may act as tumorassociated epitopes and thereby act as target for vaccination. Due to the diversity of p53 mutations, immunogenic peptides representing wild-type sequences are preferable as basis for a broadspectrum p53-targeting cancer vaccine. Furthermore, single amino acid modified p53 peptides can increase HLA-A2 binding capacity and induction of p53-specific cytotoxic T cells. A significant fraction of breast cancer patients with progressive disease obtained disease stabilization during treatment with p53-peptide loaded $\mathrm{DCs}^{17)}$. Targeting the mechanisms of tumoral immune tolerance with small-molecule inhibitors and siRNA will be expected for regulation of DCs in vivo in future ${ }^{18)}$. MAGRIT provides help in investigating the efficacy of MAGE-A3 antigen-specific cancer immunothera- peutic agents in preventing cancer relapse, when administered after tumor resection, in patients with MAGE-A3-positive stages IB, II, and IIIA nonsmall-cell lung cancer ${ }^{19)}$.

Recently, it has been shown that targeting activated tyrosine kinases can mediate striking clinical benefits in several cancers. In 2002, a mutation at the V600E amino acid of the BRAF serine/threonine kinase was described as present in over $50 \%$ of melanomas. The mutation appeared to confer a dependency by the melanoma cancer cell on its activation of the MAP kinase pathway. The frequency and specificity of this mutation suggests that it may be a potential target for immunotherapy ${ }^{20)}$.

One reason for the poor immunogenicity of many tumors may be that they cannot provide signals for CD28-mediated costimulation necessary to fully activate $\mathrm{T}$ cells. It has recently become apparent that cytotoxic T-lymphocyte antigen-4 (CTLA4 ) is a negative regulator of $\mathrm{T}$ cell activation. Blockade of the inhibitory effects of CTLA-4 can allow for, and potentiate, effective immune responses against tumor cells $\mathrm{s}^{21,22)}$.

The combination of programmed death-1 (PD-1) blockade with granulocyte macrophage colonystimulating factor (GM-CSF)-secreting tumor cell immunotherapy leads to significantly improved antitumor responses by augmenting the tumor-reactive $\mathrm{T}$-cell responses induced by cellular immunotherapy $^{23)}$.

One of the main problems in treating cancer by vaccine or immunotherapy is that tumors often evade the body's immune response. Herber DL et al. reported that a substantial proportion of DCs in tumor-bearing mice and people with cancer have high amounts of triglycerides as compared with DCs from tumor-free mice and healthy individuals. In this studies, DCs with high lipid content were not able to effectively stimulate allogeneic $\mathrm{T}$ cells or present tumor-associated antigens. Lipid-laden DCs had a reduced capacity to process antigens. Pharmacological normalization of lipid abundance in DCs with an inhibitor of acetyl-CoA carboxylase restored the functional activity of DCs and substantially enhanced the effects of cancer vaccines ${ }^{24)}$. A new study of prostate tumors has shown that a gene, FOXO3, suppresses activation of cells related to immunity and thus leads to a reduced immune response against a growing cancer ${ }^{25)}$.

Basic research is making progress, and for clinical use, some individuals respond dramatically. The appearance of the cancer antigens and the individualized treatment that considers patient immune 
response are important in the immunotherapy ${ }^{4)}$. The identification of human tumor antigens using various molecular biological and immunological techniques enabled us to develop immunotherapy in a more scientific way, along with up-to-date immune intervention techniques based on the understanding of the mechanism at each step of immunological tumor rejection. Collectively, these results indicate that DC-based vaccination could be a promising treatment modality for various cancers, but multiple hurdles must be cleared before the development of an affordable DC-based vaccination can be used worldwide.

Innovatively, the field of cancer immunotherapy received an important boost last year with the FDA's approval of the first therapeutic cancer vaccine, sipuleucel-T (Provenge). The vaccine was approved for use in some men with metastatic prostate cancer based on the results of a phase III randomized trial called IMPACT that demonstrated a more than 4-month median improvement in overall survival compared with a placebo vaccine. Sipuleucel-T is being tested in several other clinical trials, including a phase III study called PROTECT, that involves men with early-stage, nonmetastatic prostate cancer. We would like to expect future development.

\section{REFERENCES}

1. Timmerman JM, Levy R. Dendritic cell vaccines for cancer immunotherapy. Annu Rev Med, 50 : 507-529, 1999.

2. Chang KJ, Nguyen PT, Thompson JA, Thompson JA, Kurosaki TT, Casey LR, Leung EC, Granger GA. Phase I clinical traial of allogenic mixed lymphocyte culture (cytoimplant) delivered by endoscopic ultrasound-guided fine-needle injection in patients with advanced pancreatic carcinoma. Cancer, 88 : 1325-1335, 2000.

3. Schnurr M, Chen Q, Shin A, Chen W, Toy T, Jenderek C, Green S, Miloradovic L, Drane D, Davis ID, Villadangos J, Shortman K, Maraskovsky E, Cebon J. Tumor antigen processing and presentation depend critically on dendrite cell type and the mode of antigen delivery. Blood, 105 : 2465-2472, 2005.

4. Engell-Noerregaard L, Hansen TH, Andersen MH, Thor Straten P, Svane IM. Review of clinical studies on dendritic cell-based vaccination of patients with malignant melanoma: assessment of correlation between clinical response and vaccine parameters. Cancer Immunol Immunother, 58 : 1-14, 2009.

5. Steven AR, James CY, Nicholas PR. Cancer immunotherapy: moving beyond current vac- cines. Nature Medicine, 10 : 909-915, 2004.

6. De Vries IJ, Krooshoop DJ, Scharenborg NM, Lesterhuis WJ, Diepstra JH, Van Muijen GN, Strijk SP, Ruers TJ, Boerman OC, Oyen WJ, Adema GJ, Punt CJ, Figdor CG. Effective migration of antigen-pulsed dendritic cells to lymph nodes in melanoma patients is determined by their maturation state. Cancer Res, 63: 12-17, 2003.

7. Kanazawa M, Yoshihara K, Abe H, Iwadate M, Watanabe K, Suzuki S, Endoh Y, Ohki S, Takita K, Sekikawa K, Takenoshita S, Takagi T, Irisawa A, Sato Y, Ogata T, Ohto H. Case report on intratumor injection therapy of dendritic cell in advanced gastric cancer. (in Japanese) Jpn J Cancer Chemotherapy 31 : 1773-1776, 2004.

8. Koike N, Pilon-Thomas S, Mulé JJ. Nonmyeloablative chemotherapy followed by T-cell adoptive transfer and dendritic cell-based vaccination results in rejection of established melanoma. J Immunother, 31 : 402-412, 2009.

9. Kashimura S, Terashima M, Soeta N, Otani S, Hoshino M, Kanzaki N, Matsuyama S, Hoshino Y, Kogure M, Gotoh M, Ogata T, Ohto H. Experimental study for a combination chemoimmunotherapy using dendritic cells. (in Japanese) Jpn J Cancer Chemotherapy 31 : 1631-1633, 2004.

10. Iwadate M, Kanazawa M, Satou Y, Monma T, Sassa M, Suzuki S, Endoh Y, Nakamura I, Ohki S, Sekikawa K, Takenoshita S, Takagi T, Irisawa A, Oohira H, Ogata T, Ohto H. Verification of CTL assay and DTH used in monitoring of peptidepulsed dendritic cell therapy. Jpn J Cancer Chemother, 34 : 1920-1922, 2007.

11. De Vries IJ, Bernsen MR, Lesterhuis WJ, Scharenborg NM, Strijk SP, Gerritsen MJ, Ruiter DJ, Figdor CG, Punt CJ, Adema GJ. Immunomonitoring tumor-specific $\mathrm{T}$ cells in delayed-type hypersensitivity skin biopsies after dendritic cell vaccination correlates with clinical outcome. J Clin Oncol, 23 : 5779-5787, 2005.

12. Escobar A, López M, Serrano A, Ramirez M, Pérez C, Aguirre A, González R, Alfaro J, Larrondo M, Fodor M, Ferrada C, Salazar-Onfray F. Dendritic cell immunizations alone or combined with low doses of interleukin-2 induce specific immune responses in melanoma patients. Clin Exp Immunol, 142 : 555-568, 2005.

13. Kawakami Y, Fujita T, Matsuzaki Y, Sakurai T, Tsukamoto M, Toda M, Sumimoto H. Identification of human tumor antigens and its implications for diagnosis and treatment of cancer. Cancer Sci, 95 : 784-791, 2004.

14. Kulbersh JS, Day TA, Gillespie MB, Young MR. 1alpha,25-Dihydroxyvitamin $\mathrm{D}(3)$ to skew intratumoral levels of immune inhibitory CD34(+) progenitor cells into dendritic cells. Otolaryngology- 
Head and Neck Surgery, 140 : 235-240, 2009.

15. Kanazawa M, Yoshihara K, Abe H, Iwadate M, Watanabe K, Suzuki S, Endoh Y, Takita K, Sekikawa K, Takenoshita S, Ogata T, Ohto H. Effects of PSK on T and Dendritic cells differentiation in gastric or colorectal cancer patients. Anticancer Research, 25 : 443-450, 2005.

16. Shibata M, Nezu T, Kanou H, Nagata Y, Kimura T, Takekawa M, Ando K, Fukuzawa M. Immunomodulatory effects of low dose cis-diaminedichloroplatinum (cisplatin) combinated with UFT and PSK in patients with advanced colorectal cancer. Cancer Invest, 20 : 166-173, 2002.

17. Svane IM, et al. Journal of Clinical Oncology, 2006 ASCO Annual Meeting Proceedings Part I, 24 : 2577, 2006.

18. Muller AJ, Scherle PA. Targeting the mechanisms of tumoral immune tolerance with smallmolecule inhibitors. Nat Rev Cancer, 6: 613625, 2006.

19. Tyagi P, Mirakhur B. MAGRIT : the largest-ever phase III lung cancer trial aims to establish a novel tumor-specific approach to therapy. Clin Lung Cancer, 10 : 371-374, 2009.

20. Sumimoto H, Imabayashi F, Iwata T, Kawakami Y. The BRAF-MAPK signaling pathway is essential for cancer immune evasion in human mela- noma cells. J Exp Med, 203 : 1651-1656, 2006.

21. Leach DR, Krummel MF, Allison JP. Enhancement of antitumor immunity by CTLA-4 blockade. Science, 22 : 1734-1736, 1996.

22. O’Day SJ, Hamid O, Urba WJ. Targeting cytotoxic T-lymphocyte antigen-4 (CTLA-4) : a novel strategy for the treatment of melanoma and other malignancies. Cancer, 15 : 2614-2627, 2007.

23. Li B, VanRoey M, Wang C, Chen TH, Korman A, Jooss K. Anti-programmed death-1 synergizes with granulocyte macrophage colony-stimulating factor-secreting tumor cell immunotherapy providing therapeutic benefit to mice with established tumors. Clin Cancer Res, 15 : 1623-1634, 2009.

24. Herber DL, Cao W, Nefedova Y, Novitskiy SV, Nagaraj S, Tyurin VA, Corzo A, Cho HI, Celis E, Lennox B, Knight SC, Padhya T, McCaffrey TV, McCaffrey JC, Antonia S, Fishman M, Ferris RL, Kagan VE, Gabrilovich DI. Lipid accumulation and dendritic cell dysfunction in cancer. Nat Med, 16 : 880-886, 2010.

25. Watkins SK, Zhu Z, Riboldi E, Shafer-Weaver KA, Stagliano KER, Sklavos MM, Ambs S, Yagita H, Hurwitz AA. FOXO3 programs tumor-associated DCs to become tolerogenic in human and murine prostate cancer. J Clin Invest, 121 : 1361-1372, 2011. 